\title{
ENERGY PERFORMANCE IMPROVEMENT, FLOW BEHAVIOR AND HEAT TRANSFER INVESTIGATION IN A CIRCULAR TUBE WITH V-DOWNSTREAM DISCRETE BAFFLES
}

\author{
${ }^{1}$ Withada Jedsadaratanachai and ${ }^{2}$ Amnart Boonloi \\ ${ }^{1}$ Department of Mechanical Engineering, Faculty of Engineering, \\ King Mongkut's Institute of Technology Ladkrabang, Bangkok 10520, Thailand \\ ${ }^{2}$ Department of Mechanical Engineering Technology, College of Industrial Technology, \\ King Mongkut's University of Technology North Bangkok, Bangkok 10800, Thailand
}

Received 2013-07-27; Revised 2013-10-04; Accepted 2013-11-23

\begin{abstract}
A mathematical study has been carried out to examine periodic laminar flow and heat transfer characteristics in a three-dimensional isothermal wall circular tube with $45^{\circ}$ in-line V-discrete baffles. The computations are based on the Finite Volume Method (FVM) and the SIMPLE algorithm has been implemented. The fluid flow and heat transfer characteristics are presented for Reynolds numbers based on the diameter of the circular tube ranging from 100 to 1200 . To generate main streamwise vortex flows through the tested section, V-discrete baffles with an attack angle of $45^{\circ}$ are mounted in tandem with in-line arrangement and pointing downstream (V-Downstream) inserted in the middle of the tested tube. Effects of different Blockage Ratio (b/D, BR) and Pitch Ratio (P/D, PR) on heat transfer and pressure drop in the tube are studied. It is apparent that the main vortex flows can induce impinging flows on a wall of the interbaffle cavity leading to extreme increases in heat transfer rate over the circular tube. In addition, the rise in the BR and reduce of PR results in the increase in the Nusselt number and friction factor values. The computational results show that the optimum thermal enhancement factor is around 2.5 at $\mathrm{BR}=0.15, \mathrm{PR}=1$ and $\mathrm{Re}=1200$.
\end{abstract}

Keywords: Periodic Flow, Laminar Flow, Heat Transfer, V-Discrete Baffle, V-Downstream, Circular Tube

\section{INTRODUCTION}

Several designs of heat exchangers are widely used in many industrial fields such as chemical industries, aerospace industries, refrigeration applications and electronics cooling. The improvements of heat exchanger performance are in order to save energy and cost of the system. The turbulators and Vortex Generators (VG) are used to increase heat transfer rate and thermal performance in the heat exchangers. Therefore, the investigations of the effect on both turbulators and VG have been interested. The turbulators and VG are studied in term of heat transfer behavior, flow structure and performance evaluation. Almost investigators reported that the use of turbulators and VG lead to the increase in heat transfer rate but also increase in pressure loss, depended on various parameters of turbulators and VG.

The investigations are divided into two methods; experimental and numerical. This subject is use numerical method to study heat transfer and flow behavior causes of this method can show the details of behavior which are effecting for thermal performance.

Shapes and types of turbulators were studied. For example, V-baffle and inclined-baffle were studied by (Promvonge et al., 2012a; 2010a). The $45^{\circ} \mathrm{V}$-baffle and $30^{\circ}$ inclined-baffle were placed on both the upper and Corresponding Author: Withada Jedsadaratanachai, Department of Mechanical Engineering, Faculty of Engineering, King Mongkut's Institute of Technology Ladkrabang, Bangkok 10520, Thailand 
lower walls of the square duct with in-line arrangement. The Reynolds numbers in range from 100 to 2000, Blockage Ratio (b/H, BR) about 0.10-0.30 and Pitch Ratio (P/H, PR) of 1.00-2.00 were reported. They found that the V-baffle and inclined-baffle provide higher heat transfer rate, pressure loss and thermal enhancement factor than the smooth square duct for all cases. Additionally, the maximum thermal enhancement factor of V-baffle and inclined-baffle were found to be around 4.00 on both cases. Promvonge et al. (2012a) also studied $45^{\circ}$ Z-shaped baffle in the channel on both experimentally and numerically to turbulent region, $\mathrm{Re}=4400-20,400$. They reported that the numerical results are found in good agreement with experimental data. They also showed that the maximum thermal enhancement factor about 2.2 at the lowest Re for BR $=0.1$ and $\mathrm{PR}=1.5$.

The heat transfer characteristics in a three dimensional isothermal wall fluxed square duct fitted diagonally with $30^{\circ}$ angle finned tapes or $30^{\circ}$ inclinedbaffle were presented by (Sriromreun et al., 2012). They showed the different position to install of turbulators; the $30^{\circ}$ inclined-baffle in (Promvonge et al., 2010a; 2010b) placed on both the upper and lower walls while the $30^{\circ}$ inclined-baffle in (Sriromreun et al., 2012) fitted diagonally of the square duct. They also explained that the square duct fitted diagonally with $30^{\circ}$ angle finned tapes give the maximum thermal enhancement factor about 1.95 at the lowest Re.

The concept of periodically fully developed flow was introduced by (Promvonge et al., 2012a) to investigate numerically the heat transfer and flow characteristics in a duct. Since then, the periodically fully developed flow condition has been widely used to study thermal characteristics in staggered baffled channels with different baffle heights and spacing.

Sripattanapipat and Promvonge (2009) numerically studied the laminar periodic flow and thermal behaviors in a two dimensional channel fitted with staggered diamond-shaped baffles and found that the diamond baffle with half apex angle of $5-10^{\circ}$ performs slightly better than the flat baffle. Promvonge et al. (2010b) also examined numerically the laminar heat transfer in a square channel with 45 degree angled baffles placed on one wall and reported that a single streamwise vortex flow occurs and induces impingement jets on the wall of the interbaffle cavity and the BTE sidewall.

The numerical research on turbulent periodic flow and heat transfer characteristics in a three dimensional square-duct with inline $60^{\circ} \mathrm{V}$-shaped discrete thin ribs placed on two opposite heated walls was also presented by (Promvonge et al., 2011). They claim that the numerical result and measured data were found to agree well. The numerical results reported that the fully developed periodic flow and heat transfer profiles found at $\mathrm{x} / \mathrm{D}=7-11$ and thermal performance (TEF) is around 1.8 for the rib with $\mathrm{BR}=0.0725$ where the heat transfer rate is about 4.0 times above the smooth duct at lower Reynolds number.

Most of previous investigations of flow have considered the heat transfer characteristics for various baffle height and spacing ratios for porous, solid transverse or inclined baffles and V-discrete rib in square duct only. Investigators reported that the use of turbulators and VG lead to the higher not only heat transfer rate but also increase in large pressure loss. Therefore, the study on V-discrete baffles (with zero thickness) in a circular tube with the main aim to reduce the pressure loss of the test section has rarely been reported. In the present work, the numerical computations for three dimensional laminar periodic tube flows over a $45^{\circ} \mathrm{V}$-discrete baffle inserted in the middle of the tube is conducted for changes in the flow structure and thermal performance improvement. The use of the V-discrete baffle placed periodically is expected to generate longitudinal vortex flows over the tube to better mixing of fluid flows among the core and the wall regions resulting in a higher heat transfer rate in the tube.

\subsection{Flow Description}

\subsubsection{Baffle Geometry and Arrangement}

The system of interest is a circular tube with a $45^{\circ} \mathrm{V}$ discrete baffle pair inserted in the middle of the tested tube in tandem for in-line arrangement and pointing downstream (V-Downstream) as shown in Fig. 1. The flow under consideration is expected to attain a periodic flow condition in which the velocity field repeats itself from one cell to another. The concept of periodically fully developed flow and its solution procedure has been described in Promvonge et al. (2012a). The air enters the tube at an inlet temperature, $\mathrm{T}_{\mathrm{in}}$ and flows over a $45^{\circ}$ inline $\mathrm{V}$-discrete baffle pair where $\mathrm{b}$ is the baffle height, $\mathrm{D}$ set to $0.05 \mathrm{~m}$, is the tube diameter and $\mathrm{b} / \mathrm{D}$ is known as the blockage ratio, BR. The axial pitch, $\mathrm{L}$ or distance between the baffle cell is set to $\mathrm{L}=\mathrm{D}$ in which $\mathrm{L} / \mathrm{D}$ is defined as the pitch spacing ratio, $\mathrm{PR}=1$ and 1.5 . To investigate an effect of the interaction among baffles, the flow blockage ratio, $\mathrm{BR}$ is varied in a range of $\mathrm{BR}=$ $0.05-0.20$ for $\alpha=45^{\circ}$ in the present investigation. 


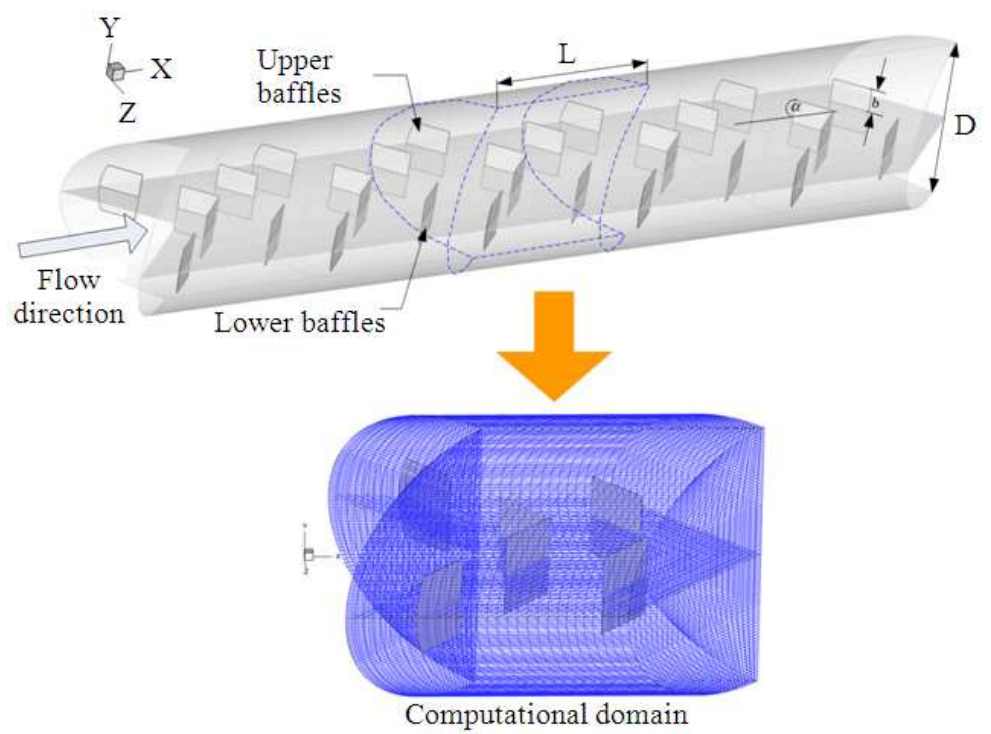

(a)

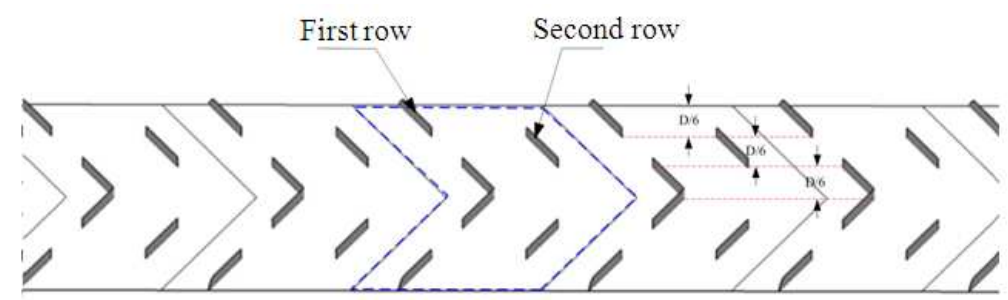

(b)

Fig. 1. (a) Tube geometry and computational domain of periodic flow and (b) details of V-discrete on a plate

\subsection{Boundary Conditions}

Periodic boundaries are used for the inlet and outlet of the flow domain. The constant mass flow rate of air with $300 \mathrm{~K}(\mathrm{Pr}=0.7)$ is assumed in the flow direction rather than constant pressure drop due to periodic flow conditions. The inlet and outlet profiles for the velocities must be identical. The physical properties of the air have been assumed to remain constant at average bulk temperature. Impermeable boundary and no-slip wall conditions have been implemented over the tube wall as well as the baffle. The constant temperature of the tube wall is maintained at $310 \mathrm{~K}$ while the baffle plate is assumed at adiabatic wall conditions.

\section{MATERIALS AND METHODS}

The mathematical model for fluid flow and heat transfer in a circular tube was developed under the following assumptions:

- Steady three-dimensional fluid flow and heat transfer
- The flow is laminar and incompressible

- Constant fluid properties

- Body forces and viscous dissipation are ignored

- Negligible radiation heat transfer

Based on the above assumptions, the tube flow is governed by the continuity, the Navier-Stokes equations and the energy equation. In the Cartesian tensor system these equations can be written as follows.

Continuity Equation (1):

$\frac{\partial}{\partial x_{i}}\left(\rho u_{i}\right)=0$

Momentum Equation (2):

$\frac{\partial\left(\rho u_{i} u_{j}\right)}{\partial x_{j}}=-\frac{\partial p}{\partial x_{i}}+\frac{\partial}{\partial x_{j}}\left[\mu\left(\frac{\partial u_{i}}{\partial x_{j}}+\frac{\partial u_{j}}{\partial x_{i}}\right)\right]$

Energy Equation (3): 
$\frac{\partial}{\partial x_{i}}\left(\rho u_{i} T\right)=\frac{\partial}{\partial x_{j}}\left(\Gamma \frac{\partial T}{\partial x_{j}}\right)$

where, $\Gamma$ is the thermal diffusivity and is given by Equation (4):

$$
\Gamma=\frac{\mu}{\operatorname{Pr}}
$$

Apart from the energy equation discretized by the QUICK scheme, the governing equations were discretized by the second order upwind scheme, decoupling with the SIMPLE algorithm and solved using a finite volume approach (Patankar, 1980). The solutions were considered to be converged when the normalized residual values were less than $10^{-5}$ for all variables but less than $10^{-9}$ only for the energy equation.

Four parameters of interest in the present work are the Reynolds number (Re), friction factor (f), Nusselt Number $(\mathrm{Nu})$ and Thermal Enhancement Factor (TEF). The Reynolds number is defined as Equation (5):

$\mathrm{Re}=\rho \overline{\mathrm{uD}} / \mu$

The friction factor, $\mathrm{f}$ is computed by pressure drop, $\Delta \mathrm{p}$ across the length of the periodic tube, $\mathrm{L}$ as Equation (6):

$\mathrm{f}=\frac{(\Delta \mathrm{p} / \mathrm{L}) \mathrm{D}}{\frac{1}{2} \rho \overline{\mathrm{u}}^{2}}$

The heat transfer is measured by local Nusselt number which can be written as Equation (7):

$\mathrm{Nu}_{\mathrm{x}}=\frac{\mathrm{h}_{\mathrm{x}} \mathrm{D}}{\mathrm{k}}$

The average Nusselt number can be obtained by Equation (8):

$\mathrm{Nu}=\frac{1}{\mathrm{~A}} \int \mathrm{Nu}_{\mathrm{x}} \partial \mathrm{A}$

The Thermal Enhancement Factor (TEF) is defined as the ratio of the heat transfer coefficient of an augmented surface, $h$ to that of a smooth surface, $h_{0}$, at an equal pumping power and given by Equation (9):

$$
\mathrm{TEF}=\left.\frac{\mathrm{h}}{\mathrm{h}_{0}}\right|_{\mathrm{pp}}=\left.\frac{\mathrm{Nu}}{\mathrm{Nu}_{0}}\right|_{\mathrm{pp}}=\left(\mathrm{Nu} / \mathrm{Nu}_{0}\right) /\left(\mathrm{f} / \mathrm{f}_{0}\right)^{1 / 3}
$$

where, $\mathrm{Nu}_{0}$ and $\mathrm{f}_{0}$ stand for Nusselt number and friction factor for the smooth tube, respectively.

The computational domain is resolved by regular Cartesian elements. For this tube flow, however, regular grid was applied throughout the domain. A grid independence procedure was implemented by using the Richardson extrapolation technique over grids with different numbers of cells. The characteristics of four grids; 53,200, 122,000, 180,400 and 321,000 cells, are used in the simulations for using the Grid Convergence Index (GCI) (Roache, 1998). The variation in $\mathrm{Nu}$ and $\mathrm{f}$ values for the $45^{\circ}$ in-line $\mathrm{V}$-discrete baffles at $\mathrm{BR}=0.15$ and $\operatorname{Re}=800$ is less than $0.25 \%$ when increasing the number of cells from 180,400 to 321,000 , thus there is no such advantage in increasing the number of cells beyond this value. Considering both convergent time and solution precision, the grid system of 180,400 cells was adopted for the current computational model.

\section{RESULTS AND DISCUSSION}

\subsection{Validation of Smooth Circular Tube}

Validation of the heat transfer and friction factor of the smooth circular tube without baffle is performed by comparison with the previous values under a similar operating condition as shown in Fig. $2 a$ and b, respectively. The current numerical smooth tube result is found to be in excellent agreement with exact solution values obtained from the open literature (Incropera et al., 2006) for both the Nusselt number and the friction factor, less than $\pm 0.28 \%$ deviation. The exact solutions of the Nusselt number and the friction factor for laminar flows over smooth tube with constant wall temperature are as follows (Incropera et al., 2006) Equation (10 and 11):

$$
\begin{aligned}
& \mathrm{Nu}_{0}=3.66 \\
& \mathrm{f}_{0}=64 / \operatorname{Re}
\end{aligned}
$$

\subsection{Flow Topology}

The flow structure in the tube with V-discrete baffles inserted in the middle of the circular tube can be displayed by considering the streamline plots as depicted in Fig. 3-6. Here the streamline in the transverse plane with temperature contour and streamline of impinging jet at various zones for the $\mathrm{V}$-discrete baffle modules are presented at $\mathrm{Re}=600$ and $\mathrm{BR}=0.15$. 
Withada Jedsadaratanachai and Amnart Boonloi / Journal of Mathematics and Statistics 9 (4): 339-348, 2013

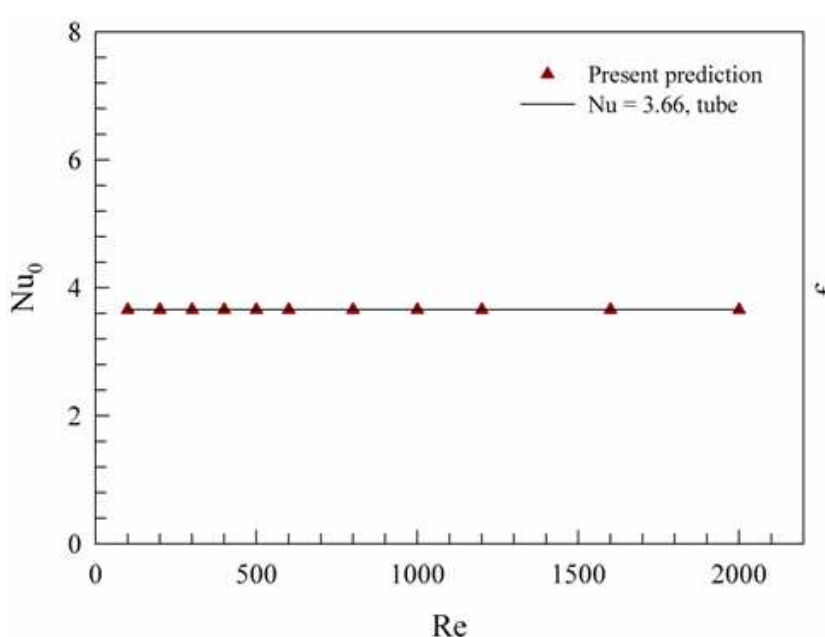

(a)

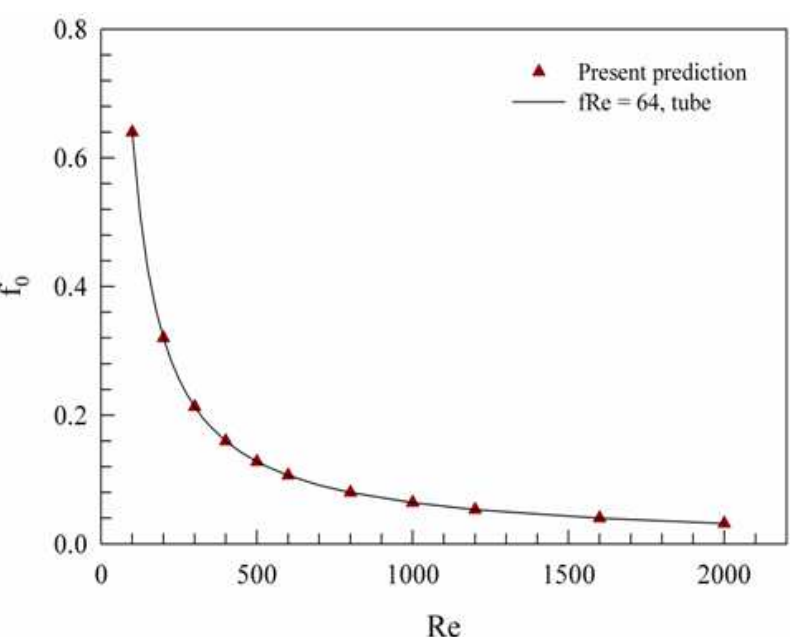

(b)

Fig. 2. Verification of (a) Nusselt number and (b) friction factor for smooth circular tube

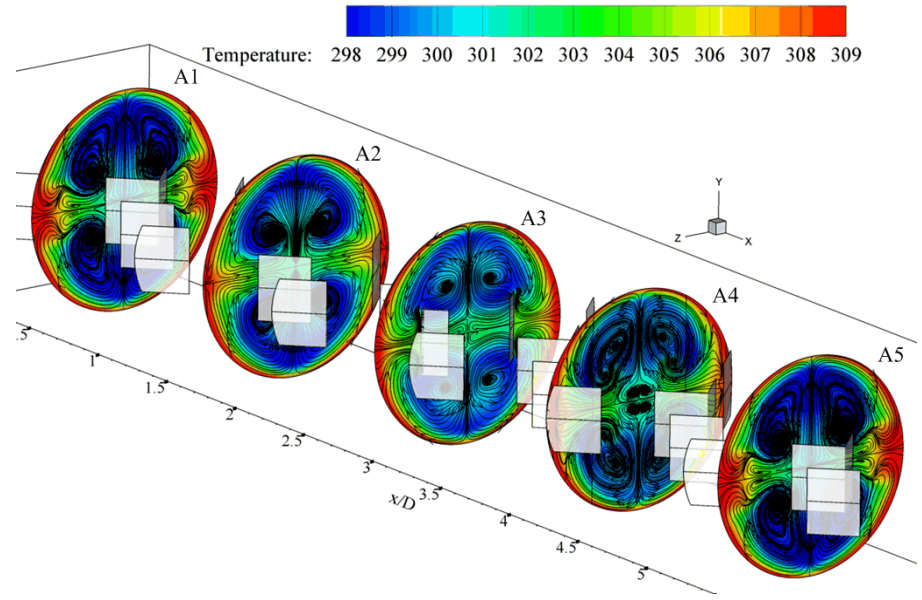

(a)

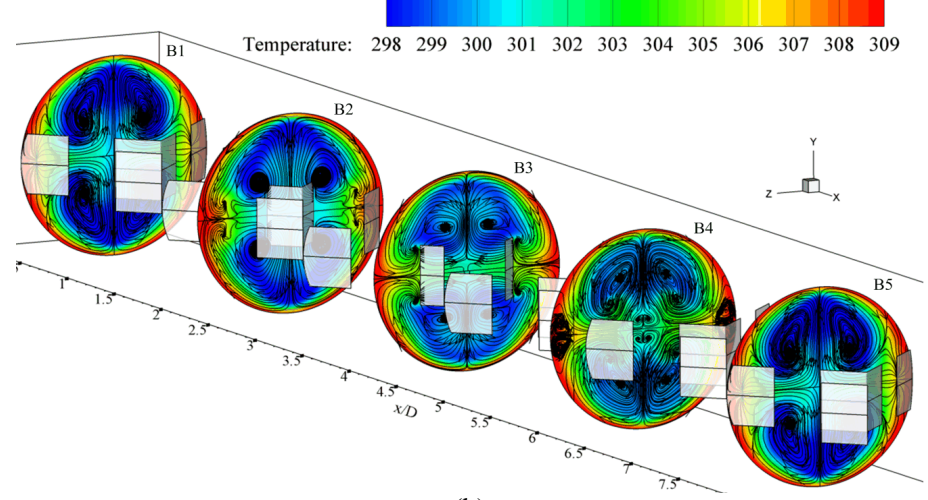

(b)

Fig. 3. Streamlines in transverse planes with temperature contour for (a) $P R=1$ and (b) $P R=1.5$ of V-discrete baffles at $R e=600$ and $\mathrm{BR}=0.15$ 


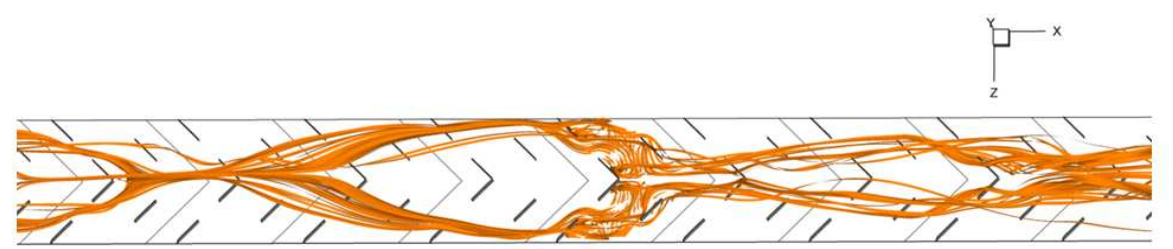

(a)
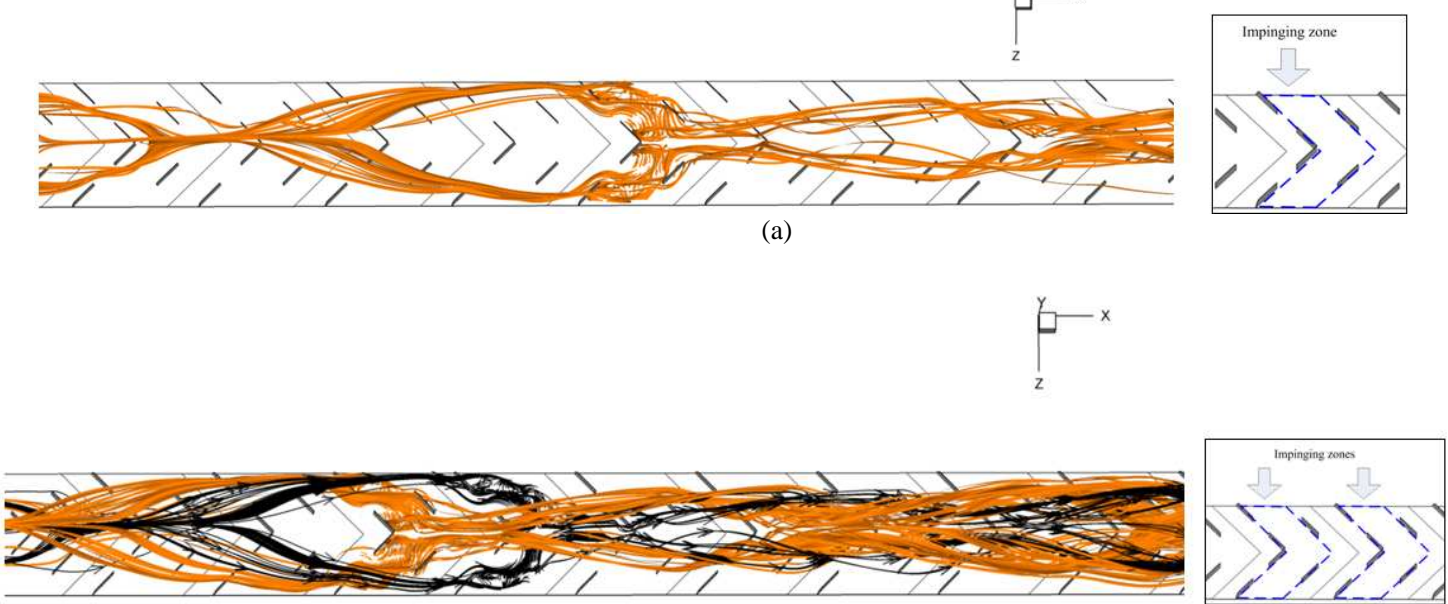

(b)

Fig. 4. Streamlines of impinging jet between first and second rows at each module for (a) one zone and (b) two zones for V-discrete baffles at $\mathrm{Re}=600, \mathrm{BR}=0.15$ and $\mathrm{PR}=1$

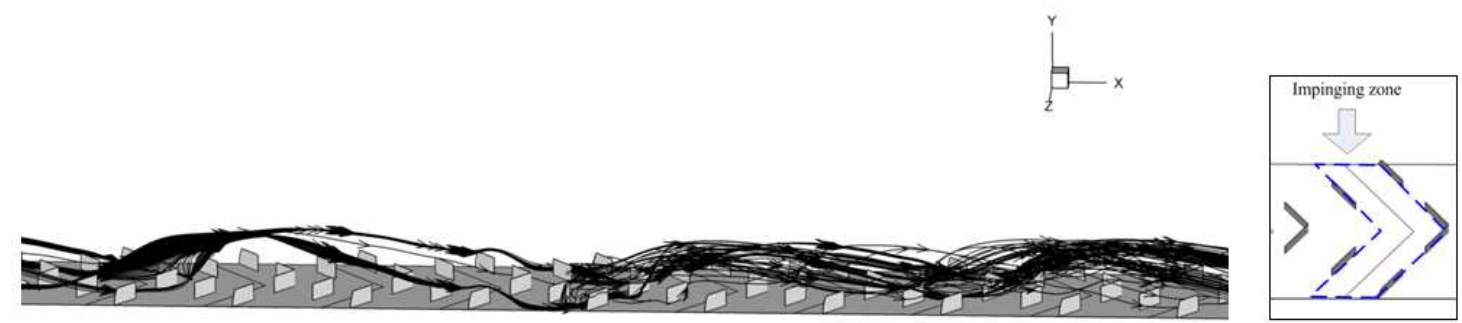

(a)

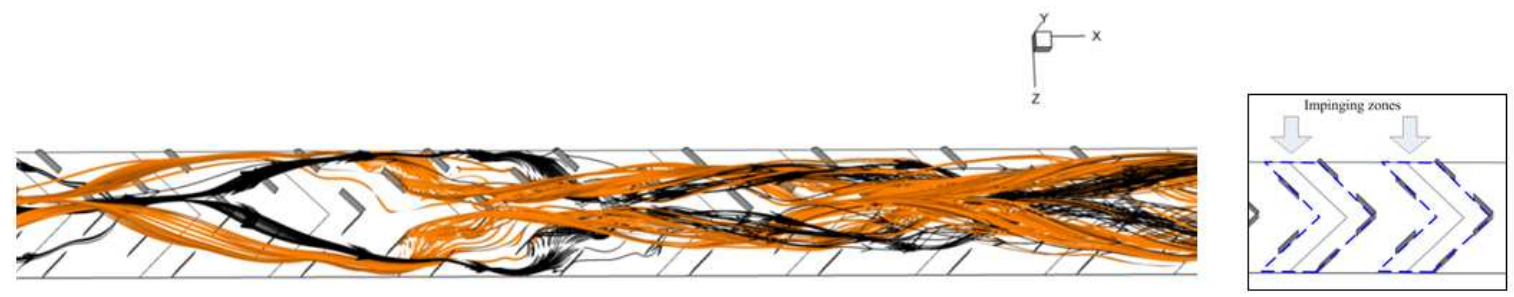

(b)

Fig. 5. Streamlines of impinging jet between upstream and downstream module for (a) one zone and (b) two zones for V-discrete baffles at $\mathrm{Re}=600, \mathrm{BR}=0.15$ and $\mathrm{PR}=1$

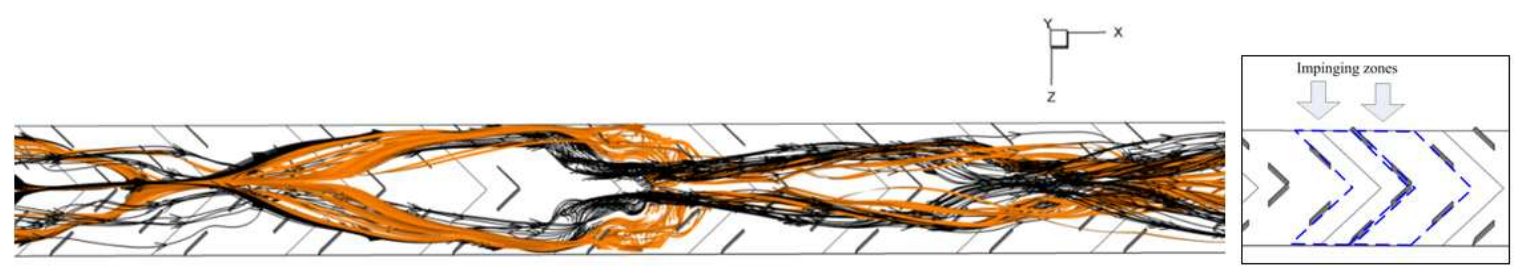

Fig. 6. Streamlines of impinging jet on both first and second rows and between module for V-discrete baffles at $\operatorname{Re}=600, B R=0.15$ and $\mathrm{PR}=1$ 
Figure 3a and b show, respectively, the streamlines in transverse planes at different locations with temperature maps superimposed for the V-discrete baffle pointing downstream (called V-downstream) for $\mathrm{PR}=1$ and 1.5. It is visible in Fig. 3a that there are four longitudinal vortex flows in the tube. Similar two counter-rotating vortices appear on the upper and the lower parts due to baffle symmetry as depicted in plane A1 to A5. This vortex flow pattern is similar for the PR $=1.5$ case, plane B1 to B5 in Fig. 3b but different in helical pitch range. A closer examination exposes that the $\mathrm{V}$-downstream produces two counter-vortex flows having a rotating direction up to the inserted plates, called "common-flow-up". The appearance of the vortex can help to increase higher heat transfer in the channel because of highly transporting the fluid from the central core to the near-wall regimes.

The plots for streamlines of impinging jet on the plate that installed V-discrete baffle between first and second row at each module for one zone and two zones are shown in Fig. 4a and b, respectively. The streamline between two modules (joint of the module) is displayed, respectively, in Fig. 5a and b for one zone and two zones. Figure $\mathbf{6}$ shows the impinging zones on both each module and among two modules. In the figures, it is found that the streamline of impinging jet occur periodically for all plotted zones. The helical vortex flow moves along the baffle cavity to the V-tip and rolls up to impinge on the wall. After impingement, the jet splits over the wall and recombines into two helical streams at the nearby baffle end to create vortex flows again. The helical pitch length of the main vortex flow is about 3D before impingement and becomes shorter (about 2D) after impingement. This means that the helical vortex flow passes three baffle modules from V-tip to the other BLE side before impingement. This behavior is identical on both the upper and lower parts so two streamwise vortices with non-uniform helical pitch is formed throughout the tested tube.

\subsection{Heat Transfer Characteristics}

Figure 3a and $\mathbf{b}$ also present the contour plot of temperature field in transverse planes for $\mathrm{PR}=1$ and 1.5, respectively, of V-discrete baffles at $\mathrm{Re}=600$ and $\mathrm{BR}=$ 0.15 . The figures show that there is a major change in the temperature field throughout the circular tube. This indicated that the vortex induces impingement flow provides a significant influence on the temperature field, because it can induce better fluid mixing between the wall and the core flow region, leading to a high temperature gradient over the heating tube wall. The higher temperature gradient can be observed where the flow impinges the tube wall. The impinge region shows that low temperature gradient occurs. However, the temperature fields for all two cases are seen to be similar and almost distributed uniformly in the entire flow indicating excellent mixing of the fluid flow.

Local $\mathrm{Nu}_{\mathrm{x}}$ contours of the circular tube wall with the $\mathrm{V}$-discrete baffles at $\mathrm{Re}=600$ and $\mathrm{BR}=0.15$ are presented in Fig. 7a and $\mathbf{b}$ for $\mathrm{PR}=1$ and 1.5, respectively. In these figures, it appears that the higher $\mathrm{Nu}_{\mathrm{x}}$ values over the wall are seen in a larger area, except for a small region on the wall where attached to the plate of the baffle installed. The peaks are observed in the impingement areas on the wall of the interbaffle cavities. This indicates a merit of employing the V-discrete baffle over the smooth circular tube for enhancing heat transfer.

The variation of the average $\mathrm{Nu} / \mathrm{Nu}_{0}$ ratio with Reynolds number values at different BRs and PRs is depicted in Fig. 8. It is worth noting that the $\mathrm{Nu} / \mathrm{Nu}_{0}$ value tends to increase with the rise of Reynolds number for all cases. The higher BR value results in the increase in the $\mathrm{Nu} / \mathrm{Nu}_{0}$ value. The $\mathrm{PR}=1$ gives the highest heat transfer rate than $\mathrm{PR}=1.5$ for all BRs. Thus, the generation of vortex flows from using the V-discrete baffles as well as the role of better fluid mixing and the impingement is the main reason for the augmentation in heat transfer of the tested tube. The use of the V-discrete baffle with the BR and PR range studied yields heat transfer rate of about 1.4-8.1 times higher than the smooth circular tube with no baffle.

\subsection{Pressure Loss}

Figure 9 presents the variation of the normalized friction factor ratio, $\mathrm{f} / \mathrm{f}_{0}$ with Reynolds number values for various BRs and PRs of V-discrete baffle. In the figure, it is noted that the $f / f_{0}$ tends to increase with the rise of Re and BR values and with decrease PR for all baffles. The use of the V-discrete baffle leads to a considerable increase in friction factor in comparison with the plain tube with no baffle. The decrease in the BR value gives rise to the reduction of friction factor. The $f / \mathrm{f}_{0}$ value for both the V-discrete baffles are found to be about 2.5-36 times over the smooth tube depending on the BR, PR and Reynolds number values. 
Withada Jedsadaratanachai and Amnart Boonloi / Journal of Mathematics and Statistics 9 (4): 339-348, 2013

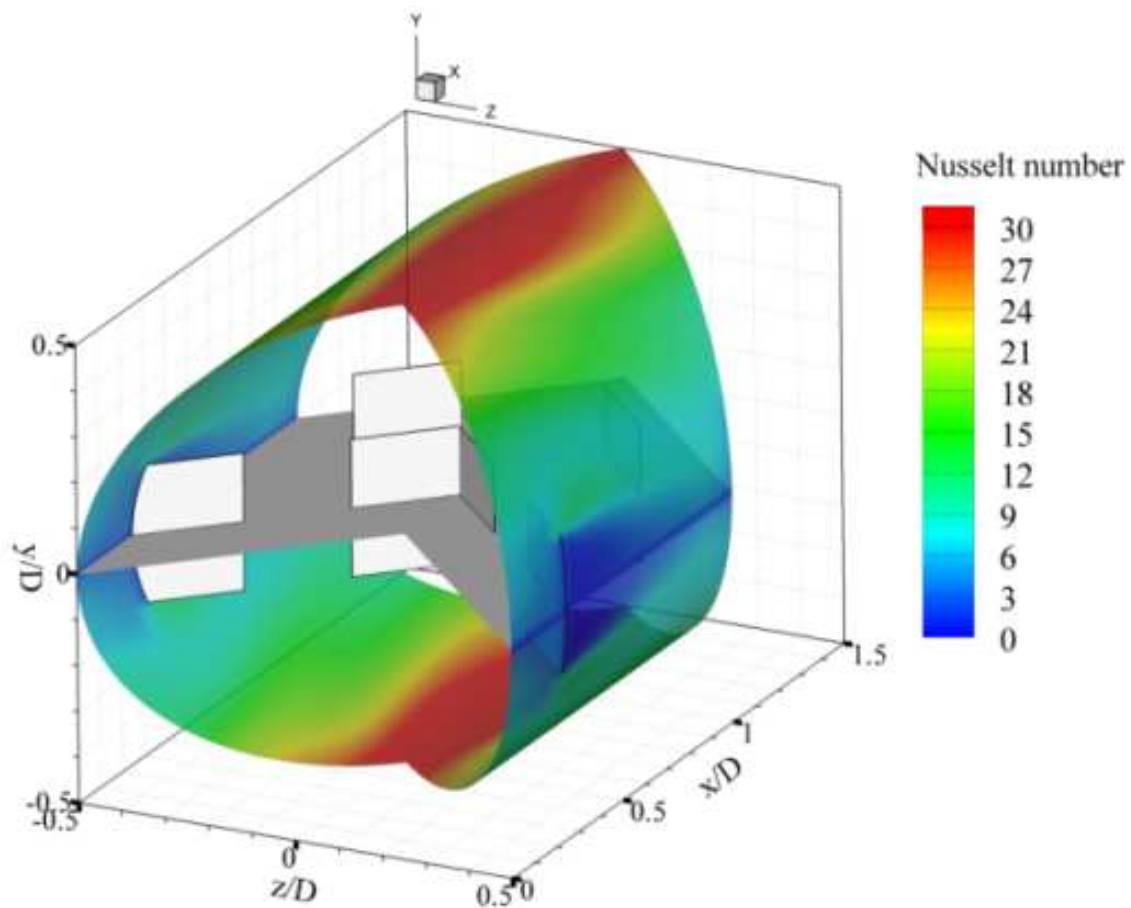

(a)

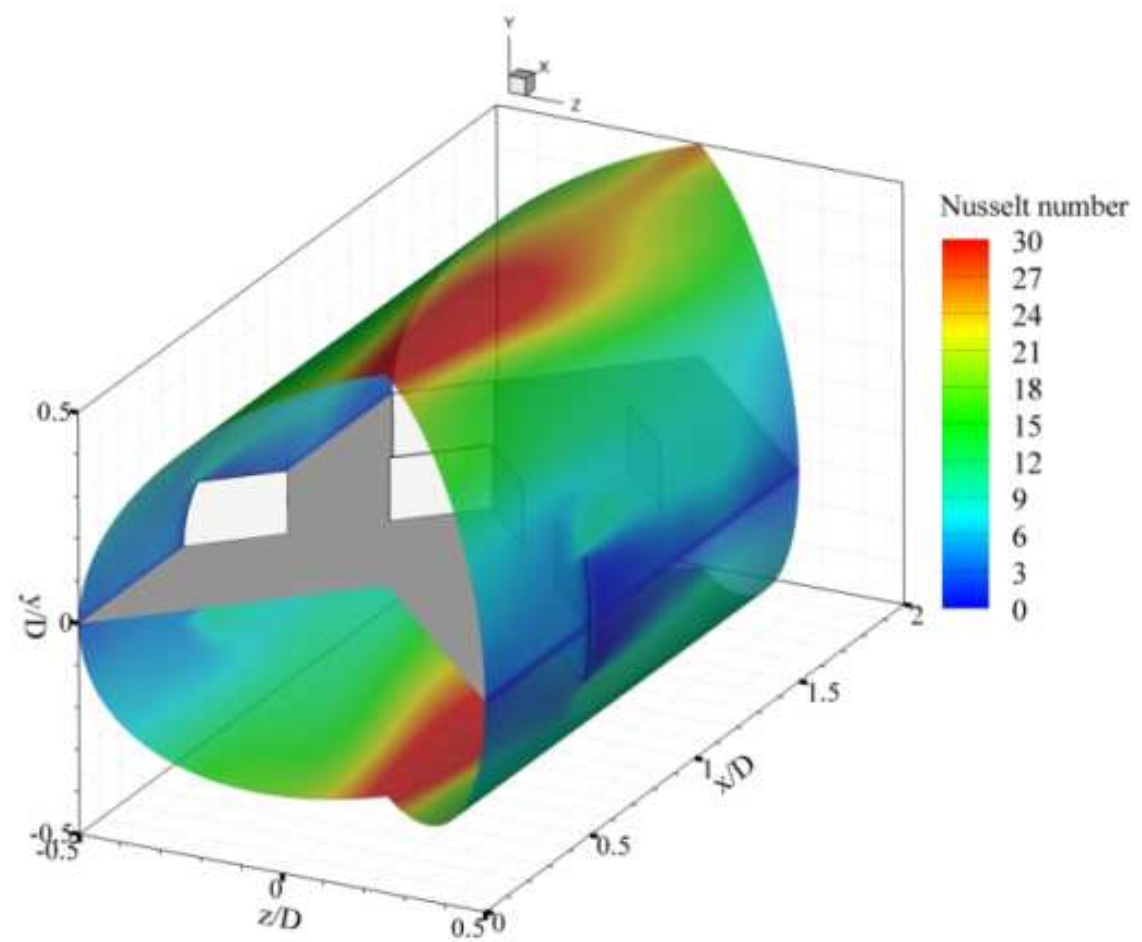

(b)

Fig. 7. $\mathrm{Nu}_{\mathrm{x}}$ Contours for (a) $\mathrm{PR}=1$ and (b) $\mathrm{PR}=1.5$ of $\mathrm{V}$-discrete baffles at $\mathrm{Re}=600$ and $\mathrm{BR}=0.15$ 
Withada Jedsadaratanachai and Amnart Boonloi / Journal of Mathematics and Statistics 9 (4): 339-348, 2013

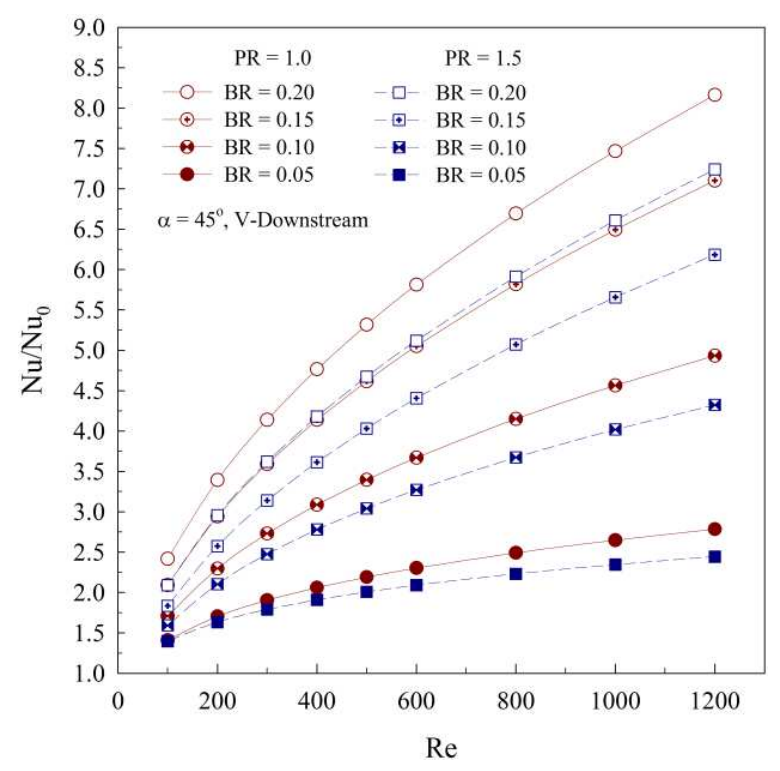

Fig. 8. Variation of $\mathrm{Nu} / \mathrm{Nu}_{0}$ with Reynolds number for various baffles BRs and PRs

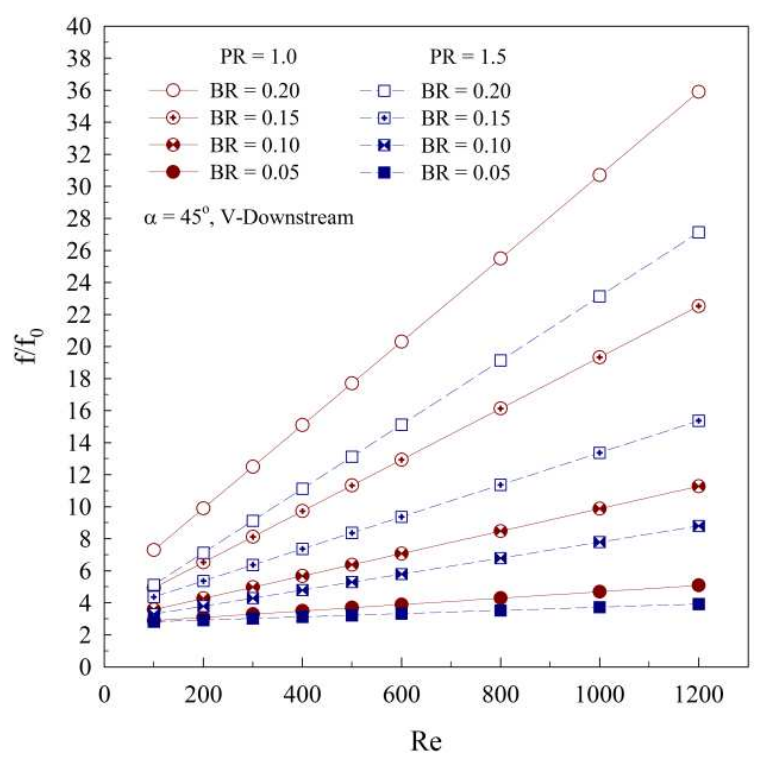

Fig. 9. Variation of $\mathrm{f} / \mathrm{f}_{0}$ with Reynolds number for baffles at various $B R s$ and $P R s$

\subsection{Performance Evaluation}

Figure 10 exhibits the variation of Thermal Enhancement Factor (TEF) for air flowing in the baffled tube. In the figure, the enhancement factor of both the Vdiscrete baffles tends to increase with the rise of Re values.

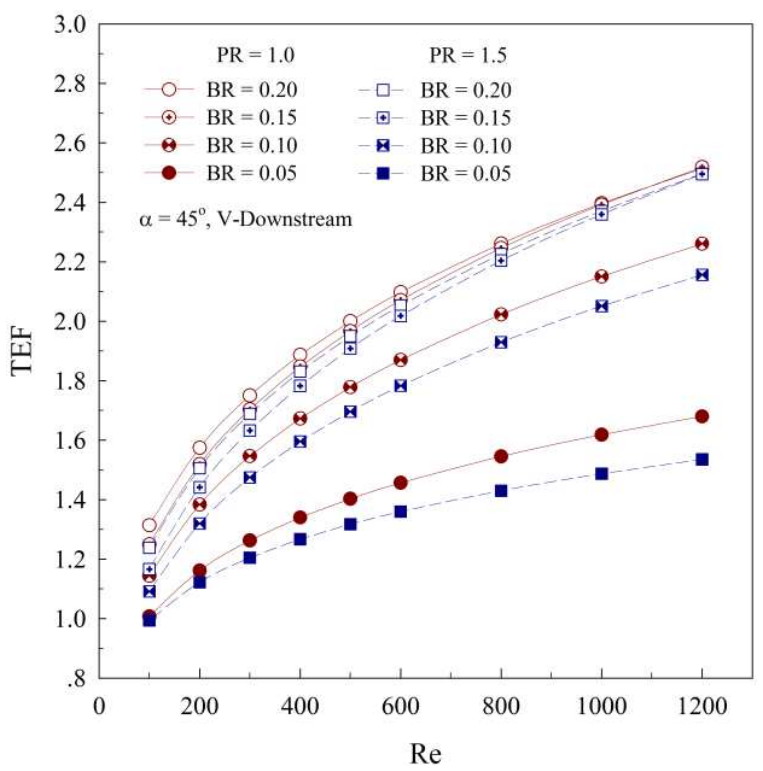

Fig. 10. Comparison of thermal enhancement factor at various BRs and PRs

All cases of the $\mathrm{V}$-discrete baffles provide the highest enhancement factor at the highest $\mathrm{Re}, \mathrm{Re}=1200$. The TEF values of both the V-discrete baffles are seen to be above unity for all BRs, PRs and vary between 1.0 and 2.5, depending on the BR, PR and Re values. The maximum TEF is found to be in cases $\mathrm{BR}=0.15$ at $\mathrm{PR}=1$.

\section{CONCLUSION}

Laminar periodic flow and heat transfer characteristics in a circular tube fitted with $45^{\circ} \mathrm{V}$ discrete baffle elements in tandem, in-line arrangements on the wall have been investigated numerically. The vortex flows created by using the $45^{\circ} \mathrm{V}$-discrete baffles help to induce impingement flows on the wall in the interbaffle cavity leading to extreme increases in heat transfer in the circular tube. The order of augmentation is 1.4-8.1 time over than smooth tube for using the $\mathrm{V}$-discrete baffles with BR $=0.05-0.20$ and $\mathrm{PR}=1-1.5$. The pressure loss is ranging from 2.5 to 36 times above the smooth tube. Thermal enhancement factors for both the V-discrete baffles are found to be in a range of 1.0-2.5 and the maximum TEF is found at $\mathrm{BR}=0.15$ and $\mathrm{PR}=1$. The $\mathrm{PR}=1$ give on both heat transfer rate and friction loss higher than $\mathrm{PR}=1.5$ for all $\mathrm{BR}$ and $\mathrm{Re}$ values. 
The investigation of the turbulent flow regime and heat transfer enhancement for in-line $45^{\circ} \mathrm{V}$-discrete baffle in a circular tube is presented in a future research.

\section{ACKNOWLEDGEMENT}

The funding of this study is supported by King Mongkut's Institute of Technology Ladkrabang, Thailand. The authors would like to thank Assoc. Prof. Dr.Pongjet Promvonge for the suggestions.

\section{REFERENCES}

Incropera, F.P., D.P. DeWitt, T.L. Bergman and A.S. Lavine, 2006. Introduction to Heat Transfer. 5rd Edn., John Wiley and Sons Inc., Hoboken, ISBN-10: 0471457272, pp: 912.

Patankar, S.V., 1980. Numerical Heat Transfer and Fluid Flow. 1st Edn., McGraw-Hill, Washington, ISBN10: 0070487405, pp: 197.

Promvonge, P., S. Skullong, S. Kwankaomeng and C. Thiangpong, 2012b. Heat transfer in square duct fitted diagonally with angle-finned tape-Part 2: Numerical study. Int. Commun. Heat Mass Trans., 39: 625-633.

DOI: 10.1016/j.icheatmasstransfer.2012.03.010

Promvonge, P., S. Sripattanapipat, S. Tamna, S. Kwankaomeng and C. Thianpong, $2010 \mathrm{~b}$. Numerical investigation of laminar heat transfer in a square channel with $45^{\circ}$ inclined baffles. Int. Commun. Heat Mass Transfer, 37: 170-177. DOI: 10.1016/j.icheatmasstransfer.2009.09.010
Promvonge, P., W. Changcharoen, S. Kwankaomeng and C. Thianpong, 2011. Numerical heat transfer study of turbulent square-duct flow through inline Vshaped discrete ribs. Int. Commun. Heat Mass Trans., 38: 1392-1399. 10.1016/j.icheatmasstransfer.2011.07.014

Promvonge, P., W. Jedsadaratanachai and S. Kwankaomeng, 2010a. Numerical study of laminar flow and heat transfer in square channel with $30^{\circ}$ inline angled baffle turbulators. Applied Thermal Eng., 30 : 1292-1303. DOI: 10.1016/j.applthermaleng.2010.02.014

Promvonge, P., W. Jedsadaratanachai, S. Kwankaomeng and C. Thianpong, 2012a. 3D simulation of laminar flow and heat transfer in V-baffled square channel. Int. Commun. Heat Mass Trans., 39: 85-93. DOI: 10.1016/j.icheatmasstransfer.2011.09.004

Roache, P.J., 1998. Verification and Validation in Computational Science and Engineering. 1st Edn., Hermosa Publishers, Albuquerque, ISBN-10: 0913478083, pp: 446.

Sripattanapipat, S. and P. Promvonge, 2009. Numerical analysis of laminar heat transfer in a channel with diamond-shaped baffles. Int. Commun. Heat Mass Trans., 36: 32-38. DOI: 10.1016/j.icheatmasstransfer.2008.09.008

Sriromreun, P., C. Thianpong and P. Promvonge, 2012. Experimental and numerical study on heat transfer enhancement in a channel with Z-shaped baffles. Int. Commun. Heat Mass Trans., 39: 945-952. DOI: 10.1016/j.icheatmasstransfer.2012.05.016 